\title{
EVALUATION OF POSTERIOR LUMBER INTERBODY FUSION WITHOUT INSTRUMENTATION IN LUMBER DEGENERATIVE DISC DISEASES
}

\author{
By
Ahmed Ismael Mohamed Ismael Khattab, Eissa Ragheb and Mohamed Negm \\ Department of Orthopedic Surgery, Faculty of Medicine of Al-Azhar University, Cairo, \\ Egypt \\ Corresponding author: Ahmed Ismael Mohamed Ismael Khattab, \\ Mobil: 01099973810, E-mail: ahmedkhattab423@yahoo.com
}

\begin{abstract}
Background: Degenerative disc disease represents a common cause of chronic low back pain that makes some disabling and requires surgical intervention. Posterior lumbar interbody fusion (PLIF) represents one of the techniques used to deal with this disabling.

Objective: To assess the results of the posterior lumbar interbody fusion (PLIF) without instrumentation in cases of degenerative disc diseases without instability.

Patient and method: This was a prospective study of twenty patients who underwent surgical lumbar laminectomy and discectomy with interbody fusion and graft for degenerative lumbar diseases that not responsive to medical treatment for 6 months at Sayed Galal Hospital, Al-Azhar Faculty of Medicine.

Result: There was a highly statistically significant decrease in the level of pain (VAS score) one week postoperatively compared to preoperative level with $\mathrm{p}$-value $<0.001$, and a statistically significant difference was found between preoperative pain (VAS score) level, and post 6 months level with p-value $<0.001$.

Conclusion: Posterior lumbar interbody fusion technique without instrumentation showed several potential benefits in the treatment of degenerative disc disease (DDD).
\end{abstract}

Keywords: PLIF, degenerative disc diseases, without instrumentation.

\section{INTRODUCTION}

Posterior lumbar interbody fusion (PLIF) is a type of spine surgery that involves approaching the spine from the back (posterior) of the body to place bone graft material between two adjacent vertebrae (interbody) to promote bone growth that joins together or "fuses" the two structures (fusion) (Mobbs et al., 2017).
A spinal fusion procedure such as a PLIF may be recommended as a surgical treatment option for patients with a condition causing spinal instability in their lower back, such as degenerative disc disease (Lykissas and Aichmair., 2013).

The primary purpose of posterior lumbar interbody fusion is to stabilize the spine (stop the motion) by restoring the 
disc height and alignment with the bone graft (Tropiano et al., 2017).

This study aimed to assess the results of the posterior lumbar Interbody fusion (PLIF) without instrumentation in cases of degenerative disc diseases without instability.

\section{PATIENTS AND METHODS}

This study was a prospective study of twenty patients who underwent surgical lumbar laminectomy and discectomy with interbody fusion for DDD that not responsive to medical treatment for 6 months in Sayed Galal Hospital from February 2019 to January 2020.

This study included adult patients aged from 30 to 55 years who suffered from back pain and radicular pain unresponsive to conservative treatment with significant degenerative disc disease without significant instability, and we excluded any associated comorbidity, e.g. severe renal disease, hepatic disease, and cardiomyopathy, associated instability as spondylolisthesis, non-degenerative lumbar diseases and other associations as the presence of infection, tumor, and trauma.

The preoperative data were noticed for all patients including clinical assessment, thorough medical history, complete general examination, VAS score, and investigated by X-ray and MRI.

Anesthesia: General anesthesia in all cases, intravenous antibiotics were given 30 minutes before incision.

Position: The patient position was prone to spinal frame, with the abdomen free and the spine flexed to open the interlaminar spaces.
Procedures: Posterior lumbar interbody fusion without instrumentation. The PLIF technique consisted of three surgical steps.

Decompression via interspinous approach partial laminectomy, flavectomy, and removal of the disc and curettage of both adjacent endplate and Interbody graft.

When decompression and stabilization were indicated, an allo-PLIF at one or two levels was performed using an autogenic graft. Prophylactic antibiotics were given preoperatively. For a successful PLIF without complications, four extremely important operative goals were obligatory: (1) Disc was removed to the anterior longitudinal ligament, which was visualized and protected from transgression, (2) To promote revascularization and remodeling of autografts, the surgeon decorticated endplates of adjacent vertebrae to expose subcortically, bleeding cancellous bone, rich with osteoprogenitor cells, to the interface with contiguous autograft; (3) Autografts filled at least $80 \%$ of disc space to provide adequate mechanical support and (4) Nerve roots was protected from traction injuries when impacting intervertebral autografts by saw cut reduction in the size of iliac optimal instrumentation.

Follow up: We followed our patients immediately after operation, one week after surgery, and six months postoperatively where we evaluated clinical and radiological finding including the clinical examination (by assessing subjective symptoms such as (low back pain and radicular pain), clinical signs, outcome scores including the visual analog score and length of postoperative 
hospital stay. Also, postoperative X-ray imaging after surgery for both groups of patients was evaluated.

Statistical analysis: All data were revised and then were presented on IBMcompatible PC by using SPSS (Statistical Package for the Social Sciences) program version 22.0.0, Microsoft Office Excel 2007, and GraphPad Prism 6 to be analyzed.

Parameters in the three studied groups and were presented in the form of mean, median, standard deviation (SD), minimum, maximum, range, and percentages. Analytical comparison between different groups was done by using student $t$ test and analysis of variance (ANOVA) for comparing parametric data when normally distributed. For comparing non parametric data, Fisher's exact test was used instead of chi-square test as Fisher's test calculates an exact $P$ value, while chi-square only calculated an approximation.

$P$ values: $P \leq 0.05$ were considered significant.

\section{Ethical considerations:}

Written and oral information were obtained from all patients' prior operation.

\section{RESULTS}

According to the demographic data, the mean age of the patients was $51.05 \pm 5.29$ with a range from $(30-55)$ years. As regard to sex distribution, 14 were males that represented $70 \%$ and 6 were females that represented 30\% (Table 1).

Table (1): Demographic data of the studied Patient $(n=20)$

\begin{tabular}{|c|c|c|}
\hline \multicolumn{2}{|c|}{ Demographic data } & No.= 20 \\
\hline \multirow{2}{*}{ Age (Years) } & Mean \pm SD & $51.05 \pm 5.29$ \\
& Range & $41-59$ \\
\hline \multirow{2}{*}{ Sex } & Females & $6(30.0 \%)$ \\
& Males & $14(70.0 \%)$ \\
\hline
\end{tabular}

As regards the diagnosis, 12 patients that represented $(60.0 \%)$ were diagnosed as L4- L5 Disc prolapsed and 8 patients that represented $(40.0 \%)$ were diagnosed as L5-S1 Disc prolapsed. Also, showed that $55 \%$ of the patients had LBP with left sciatica as a most apparent clinical picture (Table 2).

Table (2): Clinical picture and Diagnosis of the studied patients $(n=20)$

\begin{tabular}{|l|l|c|c|}
\hline \multicolumn{2}{|c|}{ Values } & No. & $\%$ \\
\hline \multirow{3}{*}{$\begin{array}{l}\text { Clinical } \\
\text { Picture }\end{array}$} & LBP + left sciatica & 11 & $55.0 \%$ \\
\cline { 2 - 4 } & LBP + right sciatica & 7 & $35.0 \%$ \\
\cline { 2 - 4 } & LBP + right sciatica + right foot drop & 1 & $5.0 \%$ \\
\cline { 2 - 4 } & weakness of hip flexior of left hip + parathesia along L4 & 1 & $5.0 \%$ \\
\hline \multirow{2}{*}{ Diagnosis } & L4- L5 Disc prolapsed & 12 & $60.0 \%$ \\
\cline { 2 - 4 } & L5-S1 Disc prolapsed & 8 & $40.0 \%$ \\
\hline
\end{tabular}


As regards blood loss level, the mean blood loss level with this technique was $442.50 \pm 131.06$ with a range from $(250-$ 700) $\mathrm{ml}$. For the operation time, the mean of the operative time was $1.43 \pm 0.40$ with a range from (1-2) hours. For the type of fusion, 20 patients that represented $(100 \%)$ went through Bony fusion with bone graft (Table 3).

Table (3): Blood loss(ml),operative time(hours) and Type of fusion of the studied patients $(n=20)$

\begin{tabular}{|c|c|c|}
\hline \multicolumn{2}{|c|}{ Values } & No.=20 \\
\hline \multirow{2}{*}{ Blood loss(ml) } & Mean \pm SD & $442.50 \pm 131.06$ \\
\cline { 2 - 3 } & Range & $250-700$ \\
\hline $\begin{array}{c}\text { Operative time } \\
\text { (Hours) }\end{array}$ & Mean \pm SD & $1.43 \pm 0.40$ \\
\cline { 2 - 3 } & Range & $1-2$ \\
\hline Type of fusion & Bony fusion with bone graft & $20(100.0 \%)$ \\
\hline
\end{tabular}

As regard to Pain (VAS Score) preoperative, 1 week postoperative and 6months postoperative, also showed that there was a highly statistically significant decrease in the level of Pain (VAS score) 1 week postoperative compared to preoperative level with p-value < 0.001and highly statistically significant difference found between Pre-operative Pain (VAS score) level and 6 months postoperative level with $\mathrm{p}$-value $<0.001$ (Table 4).

Table (4): Comparison between pain (VAS Score)pre, post 1 week, and post 6 months

\begin{tabular}{|c|c|c|c|c|c|c|}
\hline $\begin{array}{c}\text { Pain } \\
\text { (VAS score) }\end{array}$ & Pre-op & $\begin{array}{c}\text { Post-op } \\
\text { (1 week) }\end{array}$ & $\begin{array}{c}\text { Post-op } \\
\text { (6 months) }\end{array}$ & P1 & P2 & P3 \\
\hline Mean \pm SD & $8.05 \pm 0.76$ & $3.25 \pm 0.72$ & $1.60 \pm 0.68$ & \multirow{2}{*}{$0.01 \cdot$} & $0.01 \cdot$ & $0.01 \cdot$ \\
\hline Range & $7-9$ & $2-4$ & $1-3$ & & & \\
\hline Test value & \multicolumn{3}{|c|}{$1870.882^{*}$} & - & - \\
\hline P-value & $<0.001$ & & & \\
\hline Sig. & HS
\end{tabular}

P1: preoperative VS P2: VS 1week, P3: VS Post 6 months

The muscle weakness pre and Postoperative and showed that there was no statistically significant decrease in the muscle weakness preoperative and post preoperative with $\mathrm{p}$-value $=0.071$ (Table 5).

Table (5): Comparison between muscle weakness pre, and post operative

\begin{tabular}{|c|c|c|c|c|c|}
\hline \multirow{2}{*}{$\begin{array}{c}\text { Muscle } \\
\text { weakness }\end{array}$} & \multicolumn{2}{|c|}{ Pre-op } & \multicolumn{2}{|c|}{ Post-op } & \multirow{2}{*}{$\begin{array}{c}\text { P- } \\
\text { Value }\end{array}$} \\
\hline & No. & $\%$ & No. & $\%$ & \\
\hline No & 17 & $85.0 \%$ & 20 & $100.0 \%$ & \multirow{2}{*}{0.071} \\
\hline Yes & 3 & $15.0 \%$ & 0 & $0.00 \%$ & \\
\hline
\end{tabular}

\section{DISCUSSION}

Degenerative spine disease is a common process of aging in humans.
Different techniques are used to overcome this problem and minimizing operative complications. Approaches to the less 
invasive technique are gaining popularity in spinal surgery (Lee et al., 2017).

The posterior lumbar interbody fusion (PLIF) procedure has gained popularity, with indications including spinal stenosis, instability, degenerative disc disease (DDD). Interbody fusion techniques have been developed to provide solid fixation of spinal segments while maintaining load-bearing capacity and proper disc height (El-Fiky and Allam., 2016).

This study followed a prospective study of twenty patients who underwent surgical lumbar laminectomy and discectomy with interbody fusion for DDD that did not respond to medical treatment for 6 months. It included adult patients aged from 30 to 52 years and suffered from back pain and radicular pain that not respond to conservative treatment with significant degenerative disc disease without significant instability and excluded patients with associated comorbidity, associated instability as spondylolisthesis, non-degenerative lumbar diseases and any other association as the presence of infection, tumor or trauma.

The mean age of the patients was 51.05 \pm 5.29 with a range from $41-59$ years. As regard to sex distribution, 14 were males that represented $70 \%$ and 6 were females that represented $30 \%$. $(60.0 \%)$ of patients were diagnosed as L4- L5 Disc prolapsed and $(40.0 \%)$ were diagnosed as L5-S1 Disc prolapsed. 55\% of the patients had LBP with left sciatica as a most apparent clinical picture.

The mean blood loss level with this technique was $442.50 \pm 131.06$ with a range from $250-700 \mathrm{ml}$. This result matched the results found by Galgiani et al. (2016) and Elghait et al. (2019).

For the operation time, the mean of the operative time was $1.43 \pm 0.40$ with the range from 1-2hours. Al the patient went through bony fusion with bone graft.

As regard to Pain (VAS Score) preoperativly, 1 week, and 6months postoperativly, showed that there was a statistically significant decrease in the level of pain (VAS score) 1 week postoperative compared to preoperative level statistically significant difference between Preoperative Pain (VAS score) and 6 months postoperative levels.

No specific complications from the PLIF technique.

Some studies have reported that PLIF provides more reduction in VAS (Aygün et al., 2014 and Alijani et al., 2015).

Alijani et al. (2015) evaluated the pain of patients with spondylolisthesis who had undergone PLIF and reported that PLIF was related to a better outcome for pain control at 6 months after the surgery.

Aygun et al. (2014) showed those 48 months after the surgery, the PLIF group developed better results as regards the VAS.

Muscle weakness pre and postoperatively showed that there was no statistically significant decrease in the muscle weakness preoperatively and postoperatively.

\section{CONCLUSION}

Posterior lumbar inter body fusion technique without instrumentation showed several potential benefits in the treatment of degenerative disc diseases. 


\section{REFERENCES}

1. Alijani, B., Emamhadi, M., Behzadnia, H., Aramnia, A., Chabok, S. Y., Ramtinfar, S., ... and Golmohamadi, S. (2015): Posterior lumbar interbody fusion and posterolateral fusion: Analogous procedures in decreasing the index of disability in patients with spondylolisthesis. Asian Journal of Neurosurgery, 10(1), 51.

2. Aygün H, Cakar A, Hüseyinoğlu N, Hüseyinoğlu U and Celik R. (2014): Clinical and ra- diological comparison of posterolateral fusion and posterior interbody fusion techniques for multilevel lumbar spinal stabilization in manual workers. Asian Spine, 8:571-580.

3. El-Fiky T and Allam Y. (2016): Posterior lumbar interbody fusion using single polyetheretherketone transforaminal lumbar interbody fusion cage: a single- surgeon experience. Egypt Orthop J, 51:8-12.

4. Elghait HA, Akar A and Awad HA (2019): Posterior lumbar interbody fusion (PLIF) in lumbar spine infection: a retrospective study. Sci J Al-Azhar Med Fac Girls , 3:252-60.

5. Galgiani, J. N., Ampel, N. M., Blair, J. E., Catanzaro, A., Geertsma, F., Hoover, S. E., ... and Meyerson, S. L. (2016): 2016 Infectious Diseases Society of America (IDSA) clinical practice guideline for the treatment of coccidioidomycosis. Clinical Infectious Diseases, 63(6), e112-e146.

6. Lee, L. Y., Idris, Z., Beng, T. B., Young, T. Y., Chek, W. C., Abdullah, J. M., and Hieng, W. S. (2017): Outcomes of minimally invasive surgery compared to open posterior lumbar instrumentation and fusion. Asian Journal of Neurosurgery, 12(4), 620.

7. Lykissas MG and Aichmair A. (2013): Current concepts on spinal arthrodesis in degenerative disorders of the lumbar spine. World J Clin Cases. 1(1):4-12.

8. Mobbs RJ, Li JXJ and Phan K. (2017): Anterior Longitudinal Ligament Reconstruction to Reduce Hypermobility of Cervical and Lumbar Disc Arthroplasty. Asian Spine J., 11(6):943-950.

9. Tropiano, P., Giorgi, H., Faure, A., and Blondel, B. (2017): Surgical techniques for lumbo-sacral fusion. Orthopaedics\& Traumatology: Surgery \& Research, 103(1):S151-S159. 


\section{تقبيم تثتيبت مابين الفقر ات القطنبة بدون إستخدام مسامبر فقاربة في أمر اض الغضروف القطني التنكسي أحمد اسماعيل محمد اسماعيل خطاب، عيسي راغب، محمد نجم}

قسم جراحة العظام، كلية الطب، جامعة الأزهر

E-mail: ahmedkhattab423@yahoo.com

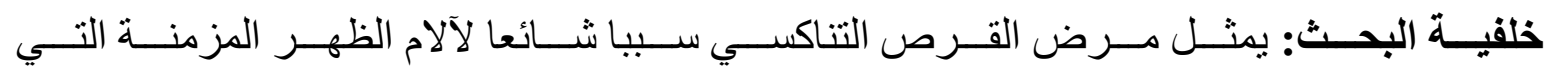

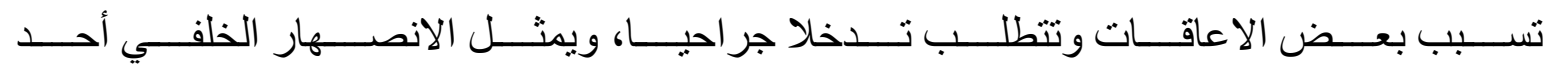
الأساليب المستخدمة لتعامل مع هذه الإعاقة.

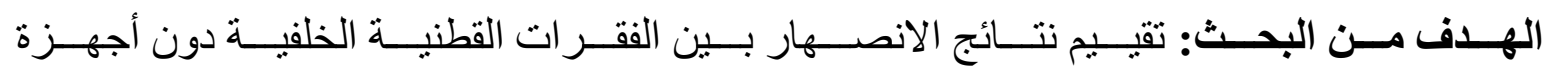
في حالات أمر اض القرص التنكسية دون اضطر اب.

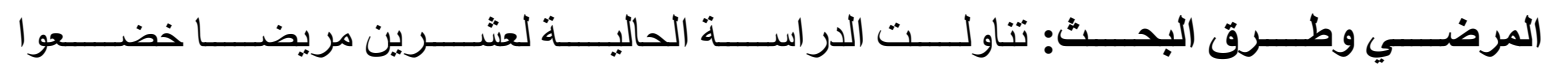

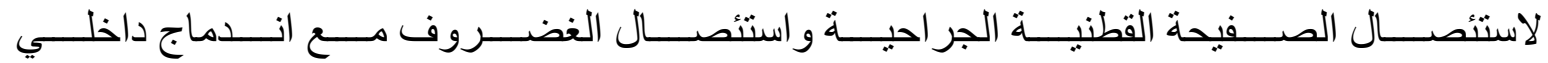

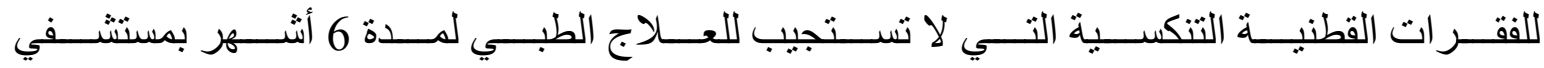
سيد جلال الجامعي.

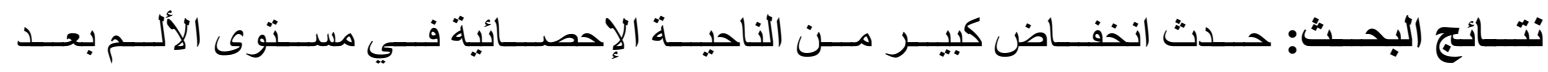

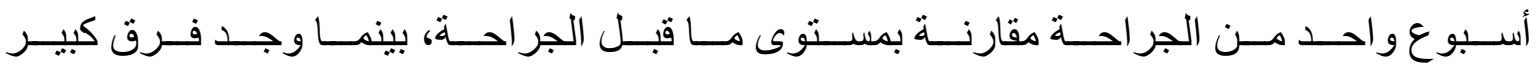
إحصائًا بين الألم المنطوق ومستوى 6 أنشهر بعد العملية الجراحية.

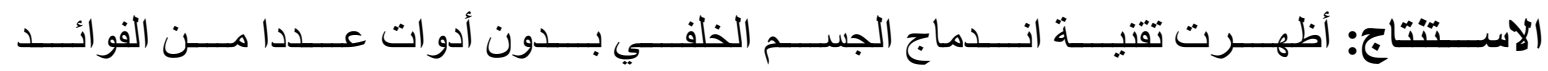
المحتملة في علاج الغضروف القطني التنكسي.

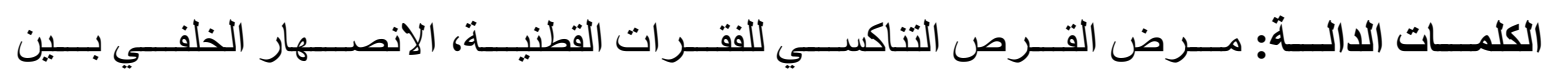
الفقر ات بدون إستخدام مسامير فقاريه. 